August 2018

\title{
A Pilot Study Exploring Nursing Knowledge of Depression and Suicidal Ideation in Kenya
}

Timothy Muga

Mater Hospital, Nairobi Kenya

Gladys Mbuthia

Aga Khan University, gladys.mbuthia@aku.edu

Samwel Gatimu

Aga Khan University, samwel.gatimu@aku.edu

Rachel Rossiter

Charles Sturt University, Australia

Follow this and additional works at: https://ecommons.aku.edu/eastafrica_fhs_sonam

\section{Part of the Nursing Midwifery Commons}

\section{Recommended Citation}

Muga, T., Mbuthia, G., Gatimu, S., Rossiter, R. (2018). A Pilot Study Exploring Nursing Knowledge of Depression and Suicidal Ideation in Kenya. Issues in Mental Health Nursing, 1-6.

Available at: https://ecommons.aku.edu/eastafrica_fhs_sonam/194 


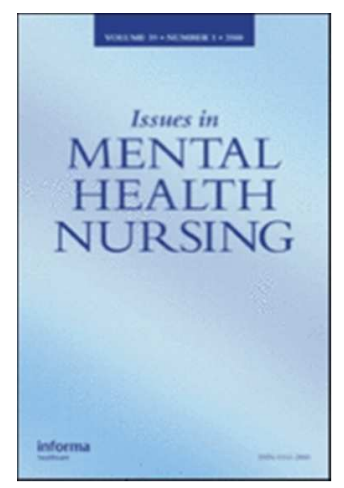

\section{A pilot study exploring nursing knowledge of depression and suicidal ideation in Kenya}

\begin{tabular}{|r|l|}
\hline Journal: & Issues in Mental Health Nursing \\
\hline Manuscript ID & UMHN-2018-0126.R2 \\
\hline Manuscript Type: & Original Research \\
\hline Keywords: & Mental disorders, mental health literacy, Kenya, Nursing, East Africa \\
\hline \multicolumn{2}{|l}{} \\
\hline
\end{tabular}

\section{SCHOLARONE"}

Manuscripts 


\section{A pilot study exploring nursing knowledge of depression and suicidal ideation Kenya}

\section{Introduction}

\section{Background}

Health literacy refers to the ability to access, understand, and use information in ways that promote and support good health (Jorm, Korten, Jacomb, Christensen, \& Henderson, 1999). Mental health literacy (MHL) means having knowledge about mental disorders that aid in their recognition, management, or prevention (Mendenhall, Frauenholtz, \& Conrad-Hiebner, 2013; Reavley, Morgan, \& Jorm, 2014). MHL includes knowledge regarding how to: achieve and maintain positive mental health; identify mental disorders, their treatment, and ways of reducing stigmatizing behaviors towards people experiencing a mental disorder; and the ability to seek help effectively (Kutcher, Wei, \& Coniglio, 2016).

Globally, the prevalence of mental disorders is increasing. The lifetime prevalence of common mental disorders is $29.2 \%$ (Steel et al., 2014), with a prevalence of $9.2 \%$ for suicidal ideation, 3.1\% for suicidal plans, and 2.7\% for suicidal attempts (Nock et al., 2008). Mental disorders are a leading cause of disabilities, and contribute $22.7 \%$ of all years lived with disabilities (Epping-Jordan et al., 2015). Depressive disorders are among the most commonly diagnosed mental disorders among young people and adults (Gulliver, Griffiths, \& Christensen, 2010), and were the second leading cause of disability in 2010 (Ferrari et al., 2013). In Kenya, the point prevalence of common mental disorders ranges from $10.8 \%$ in rural areas (Jenkins et al., 2012) to $20 \%$ in urban areas (Husain et al., 2016). Specifically, the prevalence of suicidal symptoms is $44.6 \%$ among patients with co-occurring suicidal and psychotic symptoms (Ndetei, Khasakhala, Mutiso, \& Mbwayo, 2009).

Nurses' knowledge of diagnosis and referral for patients with mental disorders is central to management and care for these patients (Ndetei, Khasakhala, Mutiso, \& Mbwayo, 2011), 
especially as nurses are the largest group in the healthcare workforce and are in close contact with the community. Poor MHL reduces the likelihood of patients receiving the right treatment for mental disorders, thereby increasing the risk for long-term adverse outcomes (Reavley et al., 2014). Levels of MHL are low globally, and significantly lower in lowresource settings such as Kenya (Almanzar et al., 2014). In Kenya, health professionals, including nurses, have limited knowledge of diagnosis and referral for children and adults with mental disorders (Ndetei et al., 2011; Ndetei et al., 2009). However, there are no available studies reporting on nurses' MHL. Therefore, we aimed to assess MHL about depression and suicidal ideation among nurses in a private urban referral hospital in Kenya.

In addition, we piloted an established MHL questionnaire in this low resource setting. The questionnaire was initially developed and validated by Australian researchers (Jorm et al., 1999), with further development and validation of specific tools for depression, anxiety disorders, and schizophrenia/psychosis (Jorm, Christensen, \& Griffiths, 2006; Jorm, Kelly, et al., 2006; Morgan, Reavley, \& Jorm, 2014; Reavley \& Jorm, 2011; Reavley et al., 2014).

\section{Objectives}

The primary aim of the study was to assess MHL about depression with suicidal ideation among nurses in a private urban referral hospital in Kenya. The secondary aim was to pilot the MHL tool covering depression with suicidal ideation developed by Reavley et al. (2014) in a Kenyan context. 


\section{Methods}

\section{Study design, setting, and sample}

A descriptive cross-sectional design was adopted for this study, involving a private urban referral hospital in Nairobi, Kenya. In total, 66 nurses working in the hospital's emergency and medical departments were recruited and provided with information leaflets about this study. Sixty nurses consented to participate and received a copy of the study questionnaire. Finally, 37 questionnaires were returned; giving a response rate of $61.7 \%$. Follow-up with the 23 participants who did not return a questionnaire yielded no additional responses, with this attributed to high workloads.

\section{MHL questionnaire}

The questionnaire to assess MHL about depression with suicidal ideation was adapted and used with permission from the original author (personal communication, December 23, 2016). The questionnaire presented a vignette of a young man experiencing symptoms of depression with suicidal ideation (Figure 1). Depression with suicidal ideation was defined according to the Diagnostic and Statistical Manual of Mental Disorders, fifth edition, as: depressed mood, loss of interest or pleasure in most activities, loss of appetite, weight loss, fatigue, or loss of energy nearly every day, feelings of worthlessness, diminished ability to think or concentrate, and recurrent thoughts of death lasting for at least two weeks (American Psychiatric Association, 2013). Participants read the vignette, identified the mental disorder, selected appropriate treatment and interventions, and responded to questions that assessed attitudes and beliefs about the identified mental disorder. Participants selected the diagnosis and treatment/intervention options from lists provided in the questionnaire. For the items covering participants' attitudes or beliefs, participants responded to statements on three-point Likert scales (e.g., "agree," "neither agree/nor disagree," and "disagree"). 
John is 30 years old. He has been feeling unusually sad and miserable for the last few weeks. Even though he is tired all the time, he has trouble sleeping nearly every night. John doesn't feel like eating and has lost weight. He can't keep his mind on his work and puts off making any decisions. Even day-to-day tasks seem too much for him. This has come to the attention of John's boss who is concerned about his lowered productivity. John feels he will never be happy again and believes his family would be better off without him. John has been so desperate, he has been thinking of ways to end his life.

Figure 1. Vignette of a young man experiencing symptoms of depression with suicidal ideation

\section{Analysis}

Returned questionnaires were reviewed for completeness and the data were coded and entered into a spreadsheet for analysis. Frequency tables and percentages were used to analyze participants' responses regarding the diagnosis, treatment, interventions, and participants' attitudes and beliefs about that disorder. Because of the small sample size, Fisher's exact test for independence was used to evaluate associations between participants' sociodemographic characteristics (age, sex, qualifications, and years of experience) and the mental disorder they identified. Questionnaires with missing responses to certain items (evaluated on Likert scales) were included in the data analysis because of the small sample size.

\section{Ethical considerations}

A The Aga Khan University Research Ethics Committee approved this study (Ref No. 2017/REC-24 (v1)). All participants provided written informed consent before receiving a questionnaire. Anonymized questionnaires were used to assure confidentiality. Access to the data was restricted to the core research team. The Research Ethics Committee initially 
declined the study protocol targeting nurses from all departments across the hospital, suggesting that it was only nurses in medical or accident and emergency departments who had contact with people experiencing mental illness. Therefore, ethics approval was only obtained to recruit nurses working in the medical ward and accident and emergency department of the participating hospital.

\section{Results \\ Participants' characteristics}

Of the 60 participants who consented to join the study, 37 (25 females, 12 males) completed the questionnaire (61.7\% response rate). The majority of participants were aged 20-29 years $(n=21)$, were Diploma in Nursing graduates $(n=30)$, had worked for 5 years or less $(n=18)$, and had previously managed a patient with mental illness $(n=36)$.

\section{John's problem and possible causes}

All 37 participants responded to the question asking what was wrong with John. Three participants (female, aged 20-29 years and with less than 10 years of work experience) correctly identified the diagnosis (depression with suicidal ideation) and 24 partially recognized the diagnosis; 23 identified depression but not suicidal ideation, and one selected suicidal ideation but not depression. One participant identified the problem as schizophrenia, and nine were not sure of the diagnosis (Table 1). Nine participants; a majority who were male, aged 20-29 years, diploma graduates and with 1-5 years' work experience could not diagnose the problem and one identified the problem as schizophrenia. The identified diagnoses did not differ significantly by participants' gender, age, qualification, and years of experience. However, all participants noted that the symptoms were distressing, and 34 recognized the seriousness of the problem. The most likely causes of John's problems were 
thought to be poor coping mechanisms $(43.2 \%)$, family issues or problems $(24.3 \%)$, and drugs and substance abuse $(8.1 \%)$ (Table 2$)$.

\section{[Table 1 and 2 near here]}

\section{Perceived helpfulness of interventions}

Participants identified psychiatrists $(56.8 \%)$, counselors $(32.4 \%)$, and psychologists $\left(1 \theta_{-} .8 \%\right)$ as the most helpful care providers. Antidepressants $(83.8 \%)$ were regarded as the most helpful medication and psychotherapy $(40.5 \%)$ as the most helpful treatment activity. If professionally managed, $40.5 \%$ of participants thought that John would achieve full recovery with no further problems, $54.1 \%$ thought he would recover with the possibility of recurrence, and $2.7 \%$ thought he would partially recover. However, $83.8 \%$ of participants noted that John's condition would worsen if not professionally managed, but $16.2 \%$ thought he would get some level of recovery without management (Table $3 \underline{1}$ ).

[Table 3-1 near here]

\section{Perception and attitudes towards people with problems such as John's}

Participants' perceptions of people with depression with suicidal ideation were characterized by fear, with $46 \%$ agreeing that "people with a problem like John's are dangerous," and 45.9\% agreeing that "people with a problem like John's are unpredictable." Interestingly, $34 \%$ of participants agreed that "people with a problem like John's could snap out of it if they wanted." (Table $4 \underline{2})$

[Table 4-2 near here]

Willingness to interact with a people with a problem such as John's 
Participants responded positively to statements exploring their willingness to interact with people with John's problem. In total, $86 \%$ were willing to make friends and socialize with people with similar problems to John's while $77 \%$ and $65 \%$ were willing to work and live closely, but only $37.1 \%$ were willing to have a person with a similar problem to John marry into their family-(Table 5).

\section{[Table 5 near here]}

\section{Suitability of the MHL questionnaire}

Participants completed the MHL questionnaire without reporting difficulties or seeking clarification on any items. However, not all participants completed all questions. Likert scale ratings of the usefulness of medicines and possible causes of John' problem showed a large amount of missing data. Missing data for the question on the perceived helpfulness of medicine as an intervention ranged from $2.7 \%$ for antidepressants to $\underline{18.9 \% \text { for tranquilizers }}$ and $21.6 \%$ for tranquilizers antibiotics(Supplementary Table 1). In addition, missing data for questions regarding possible causes included $2.7 \%$ for "poor coping mechanisms" and "a weak character" to $10.8 \%$ for "fate or destiny," "poor health," "bewitched," and "lack of friends." Other questions had minimal $\underline{(2.7 \% \text { to } 5.4 \%)}$ or no missing data-(Supplementary Table 2).

\section{Discussion}

\section{Key findings}

The low level of MHL among nurses in this study indicated that these nurses had difficulty recognizing depression with suicidal ideation, its causes, and appropriate treatments. These results showed lower levels of knowledge than reported in an earlier study in a general hospital in Kenya, which indicated that $34.2 \%$ of nurses were knowledgeable about mental 
disorders and $5.1 \%$ were aware of the appropriate treatment for mental disorders (Ndetei et al., 2011). The findings of this study contrast with two studies from the United Arab Emirates that used the same tool. These studies reported on the MHL of nurses in two different settings; $53.7 \%$ of pediatric hospital staff (Al-Yateem et al., 2017) and 49.3\% of school nurses (Al-Yateem, Rossiter, Robb, \& Slewa-Younan, 2018) correctly identified the condition described in the vignette. Both of these previous studies suggested that their findings were concerning and indicated the importance of focusing on curriculum development for future nurses and culturally relevant professional development for the existing nursing workforce.

Participants' choice of interventions appeared to be strongly rooted in their professional knowledge as nurses. In the African context, community responses to people displaying symptoms indicative of a mental disorder are generally influenced by a range of superstitions and myths (Ndetei et al., 2011). Participants in the present study chose interventions that were biomedical in nature, rather than culturally determined (e.g., herbalists). Similar results were seen in the choice of medications and treatment, with the majority of participants choosing contemporary over traditional medications. Although the response options reflected medically prescribed medications, $78 \%$ identified antipsychotic medication as helpful, which is inconsistent with treatment guidelines that outline antidepressants as first-line therapy for severe depression (Ministry of Medical Services \& Ministry of Public Health and Sanitation, 2009, p. 171). It might be that nurses' inability to recognize that the person in the vignette was experiencing depression with suicidal thoughts might have further confounded the choice of appropriate medication.

In contrast to the biomedical perspective shown in intervention choices, participants' perceptions of people experiencing symptoms of a mental disorder were characterized by fear, mistrust, and lack of empathy. This is congruent with participants' responses to the 
question about the cause/reason for the mental disorder (i.e., poor coping mechanisms and a weak character). These findings resonate with earlier work undertaken in Africa that revealed a lack of empathy toward people with mental disorders, beliefs that evil powers or familial defects were the cause of mental illness, and a belief that patients identified as mentally ill were responsible for their illness (Gureje, Lasebikan, Ephraim-Oluwanuga, Olley, \& Kola, 2005; Ndetei et al., 2011). The potential impact of this limited knowledge in relation to the causes and management of mental disorders in combination with apparent mistrust, fear, and lack of empathy raises concern as to the quality of care that may be provided to people experiencing symptoms indicative of a mental disorder.

Interestingly, younger nurses who had recently graduated were able to correctly identify the condition shown in the vignette; suggesting that they are potentially better prepared to identify mental disorders. This calls for improvement of knowledge and skills in diagnosis and treatment of depression with suicidal ideation among older nurses. However, considering the small sample size in this study, this assertion would need to be further tested by replicating this study with a bigger sample size across a range of different healthcare settings.

\section{Suitability of the questionnaire}

This study piloted the use of a MHL questionnaire initially developed in the Australian context and validated across a range of different cohorts (Jorm, Christensen, et al., 2006; Morgan et al., 2014; Reavley \& Jorm, 2011; Reavley et al., 2014; Slewa-Younan et al., 2014), including health professionals and community members. This study piloted the MHL questionnaire with a select cohort of nurses employed in a Kenyan urban private referral hospital. This pilot study indicated that the tool has potential to assess MHL more broadly among nurses in the Kenyan context. There were missing data for items related to the usefulness of medicines and possible causes of John' problem, which might be indicative of participants' low level of MHL and existing health belief systems (Al-Yateem et al., 2017; 
Al-Yateem et al., 2018). Conversely, there might have been difficulties in interpreting the questions. Further testing of the questionnaire is therefore necessary. It is also necessary to ensure context-specific options commonly used in Kenya are included in the range of interventions listed. A qualitative assessment of participants' understanding, or interpretation of the questions is required, in particular, those with missing data. On completion of these steps, the questionnaire should be further tested with a statistically significant sample across a range of healthcare settings.

\section{Strengths and limitations}

Recruitment of participants was limited to one private, urban-based hospital. Therefore, the results of this study cannot be generalized to nurses employed in other settings in Kenya. The small sample size was another limitation in this study; however, this small sample size could be seen as appropriate for a pilot study seeking to trial the MHL questionnaire. As previously noted, the sample size was limited because of the Research Ethics Committee requirement to restrict recruitment to nurses who would be likely to manage patients with mental health problems in the hospital. This was because the Committee felt that persons presenting with symptoms indicative of mental disorder are normally seen in the emergency department and sometimes admitted to the medical department. However, recruitment of nurses from across the entire workforce in the study institution would not seem to contravene any ethical principles. This decision may perhaps indicate a low level of MHL more broadly, with the Committee unaware that mental disorders do not occur in isolation, and that any patient admitted for a physical complaint may also develop or already be experiencing a comorbid mental disorder (Clarke \& Currie, 2009; Di Benedetto et al., 2014; King-Wing Ma \& KamTao Li, 2016). The present authors would argue that all nurses require a high level of MHL to effectively recognize, identify, manage, and appropriately refer patients experiencing symptoms of a mental disorder. Undertaking this study has suggested a need for improved 
MHL more broadly among health professionals. However, despite the small sample, this study provided insights into participating nurses' MHL and the suitability of the MHL questionnaire in a low-resource setting.

\section{Conclusion}

The present study revealed poor MHL regarding depression with suicidal ideation among nurses in a private urban hospital in Kenya. These findings help bridge the evidence gap in MHL in low resource countries, and highlight a major challenge in mental health promotion and prevention in Kenya. Low levels of MHL among the participants' highlights the need for continuous nursing education among practicing nurses and curriculum enhancement for future nurses, with emphasis on mental health promotion and practice. Further studies designed to assess MHL among nurses using a broader sample and involving various settings (hospital, schools, community facilities) are needed to inform future curriculum development and professional development for the existing workforce, in an important step toward addressing the disparity in mental healthcare in Kenya. 


\section{Disclosure of interest}

The authors declare that they have no competing interests.

\section{Acknowledgement}

The authors would like to acknowledge Dr. Eunice Ndirangu for her contribution in the design of the study, James Orwa for his contribution in preliminary data analysis, Audrey Holmes for proofreading and editing services, and all nurses who participated in the study.

\section{Funding}

This study did not receive funding.

\section{Availability of data and materials}

The data that support the findings of this study are available from the corresponding author upon reasonable request, and on receiving permission from the Aga Khan University.

\section{References}

Al-Yateem, N., Rossiter, R., Robb, W., Ahmad, A., Elhalik, M. S., Albloshi, S., \& SlewaYounan, S. (2017). Mental health literacy among pediatric hospital staff in the United Arab Emirates. BMC Psychiatry, 17(1), 390. doi: 10.1186/s12888-017-1556-Z

Al-Yateem, N., Rossiter, R. C., Robb, W. F., \& Slewa-Younan, S. (2018). Mental health literacy of school nurses in the United Arab Emirates. Int J Ment Health Syst, 12, 6. doi: 10.1186/s13033-018-0184-4

Almanzar, S., Shah, N., Vithalani, S., Shah, S., Squires, J., Appasani, R., \& Katz, C. L. (2014). Knowledge of and attitudes toward clinical depression among health providers in Gujarat, India. Ann Glob Health, 80(2), 89-95. doi: 10.1016/j.aogh.2014.04.001

American Psychiatric Association. (2013). Diagnostic and statistical manual of mental disorders. Washington, United States of America: American Psychiatric Association. 
Clarke, D. M., \& Currie, K. C. (2009). Depression, anxiety and their relationship with chronic diseases: a review of the epidemiology, risk and treatment evidence. Medical Journal of Australia, 190(7), S54.

Di Benedetto, M., Lindner, H., Aucote, H., Churcher, J., McKenzie, S., Croning, N., \& Jenkins, E. (2014). Co-morbid depression and chronic illness related to coping and physical and mental health status. Psychology, Health \& Medicine, 19(3), 253-262. doi: $10.1080 / 13548506.2013 .803135$

Epping-Jordan, J. E., Van Ommeren, M., Ashour, H. N., Maramis, A., Marini, A., Mohanraj, A., . . . Silove, D. (2015). Beyond the crisis: building back better mental health care in 10 emergency-affected areas using a longer-term perspective. International journal of mental health systems, 9(1), 15. doi: 10.1186/s13033-015-0007-9

Ferrari, A. J., Charlson, F. J., Norman, R. E., Patten, S. B., Freedman, G., Murray, C. J., . . . Whiteford, H. A. (2013). Burden of depressive disorders by country, sex, age, and year: findings from the global burden of disease study 2010. PLoS Medicine, 10(11), e1001547. doi: 10.1371/journal.pmed.1001547

Gulliver, A., Griffiths, K. M., \& Christensen, H. (2010). Perceived barriers and facilitators to mental health help-seeking in young people: a systematic review. BMC Psychiatry, 10(1), 113. doi: https://doi.org/10.1186/1471-244X-10-113

Gureje, O., Lasebikan, V. O., Ephraim-Oluwanuga, O., Olley, B. O., \& Kola, L. (2005). Community study of knowledge of and attitude to mental illness in Nigeria. British Journal of Psychiatry, 186, 436-441. doi: 10.1192/bjp.186.5.436

Husain, N., Mukherjee, I., Notiar, A., Alavi, Z., Tomenson, B., Hawa, F., . . Chaudhry, N. (2016). Prevalence of Common Mental Disorders and its Association with Life Events and Social Support in Mothers Attending a Well-Child Clinic. SAGE Open, 6(4), 215824401667732. doi: 10.1177/2158244016677324 
Jenkins, R., Njenga, F., Okonji, M., Kigamwa, P., Baraza, M., Ayuyo, J., . . . Kiima, D. (2012). Prevalence of common mental disorders in a rural district of Kenya, and socio-demographic risk factors. International Journal of Environmental Research and Public Health, 9(5), 1810-1819. doi: 10.3390/ijerph9051810

Jorm, A. F., Christensen, H., \& Griffiths, K. M. (2006). The public's ability to recognize mental disorders and their beliefs about treatment: changes in Australia over 8 years. Australian and New Zealand Journal of Psychiatry, 40(1), 36-41. doi: 10.1080/j.1440-1614.2006.01738.x

Jorm, A. F., Kelly, C. M., Wright, A., Parslow, R. A., Harris, M. G., \& McGorry, P. D. (2006). Belief in dealing with depression alone: results from community surveys of adolescents and adults. Journal of Affective Disorders, 96(1-2), 59-65. doi: 10.1016/j.jad.2006.05.018

Jorm, A. F., Korten, A. E., Jacomb, P. A., Christensen, H., \& Henderson, S. (1999). Attitudes towards people with a mental disorder: a survey of the Australian public and health professionals. Australian and New Zealand Journal of Psychiatry, 33(1), 77-83. doi: 10.1046/j.1440-1614.1999.00513.x

King-Wing Ma, T., \& Kam-Tao Li, P. (2016). Depression in dialysis patients. Nephrology, 21(8), 639-646. doi: 10.1111/nep.12742

Kutcher, S., Wei, Y., \& Coniglio, C. (2016). Mental Health Literacy: Past, Present, and Future. Canadian Journal of Psychiatry. Revue Canadienne de Psychiatrie, 61(3), 154-158. doi: 10.1177/0706743715616609

Mendenhall, A. N., Frauenholtz, S., \& Conrad-Hiebner, A. (2013). Provider Perceptions of Mental Health Literacy Among Youth. Child and Adolescent Social Work Journal, 31(3), 281-293. doi: 10.1007/s10560-013-0321-5 
Ministry of Medical Services, \& Ministry of Public Health and Sanitation. (2009). Clinical guidelines for management and referral of common conditions at level 4-6: hospital (M. Crouch Ed. Vol. III). Nairobi, Kenya: Ministry of Medical Services and Ministry of Public Health and Sanitation.

Morgan, A. J., Reavley, N. J., \& Jorm, A. F. (2014). Beliefs about mental disorder treatment and prognosis: comparison of health professionals with the Australian public. Australian and New Zealand Journal of Psychiatry, 48(5), 442-451. doi: $10.1177 / 0004867413512686$

Ndetei, D. M., Khasakhala, L. I., Mutiso, V., \& Mbwayo, A. W. (2011). Knowledge, attitude and practice (KAP) of mental illness among staff in general medical facilities in Kenya: practice and policy implications. African Journal of Psychiatry, 14(3). doi: 10.4314/ajpsy.v14i3.6

Ndetei, D. M., Khasakhala, L. I., Mutiso, V. N., \& Mbwayo, A. W. (2009). Recognition of depression in children in general hospital-based paediatric units in Kenya: practice and policy implications. Ann Gen Psychiatry, 8, 25. doi: 10.1186/1744-859X-8-25

Nock, M. K., Borges, G., Bromet, E. J., Alonso, J., Angermeyer, M., Beautrais, A., . . . Williams, D. (2008). Cross-national prevalence and risk factors for suicidal ideation, plans and attempts. British Journal of Psychiatry, 192(2), 98-105. doi: 10.1192/bjp.bp.107.040113

Reavley, N. J., \& Jorm, A. F. (2011). Recognition of mental disorders and beliefs about treatment and outcome: findings from an Australian national survey of mental health literacy and stigma. Australian and New Zealand Journal of Psychiatry, 45(11), 947956. doi: $10.3109 / 00048674.2011 .621060$

Reavley, N. J., Morgan, A. J., \& Jorm, A. F. (2014). Development of scales to assess mental health literacy relating to recognition of and interventions for depression, anxiety 
disorders and schizophrenia/psychosis. Australian and New Zealand Journal of Psychiatry, 48(1), 61-69. doi: 10.1177/0004867413491157

Slewa-Younan, S., Mond, J., Bussion, E., Mohammad, Y., Guajardo, M. G. U., Smith, M., . . . Jorm, A. F. (2014). Mental health literacy of resettled Iraqi refugees in Australia: knowledge about posttraumatic stress disorder and beliefs about helpfulness of interventions. BMC Psychiatry, 14(1), 320. doi: https://doi.org/10.1186/s12888-014$\underline{0320-\mathrm{x}}$

Steel, Z., Marnane, C., Iranpour, C., Chey, T., Jackson, J. W., Patel, V., \& Silove, D. (2014). The global prevalence of common mental disorders: a systematic review and metaanalysis 1980-2013. International Journal of Epidemiology, 43(2), 476-493. doi: 10.1093/ije/dyu038 
Table 1. Percentages of participant's perception of helpfulness of interventions for the vignette

\begin{tabular}{|c|c|c|c|c|c|}
\hline Intervention & Helpful & Neither & Harmful & $\begin{array}{l}\text { Don't } \\
\text { know }\end{array}$ & $\begin{array}{c}\text { Most } \\
\text { helpful }^{\mathrm{a}}\end{array}$ \\
\hline \multicolumn{6}{|l|}{ Person/service } \\
\hline A doctor & 79.4 & 5.9 & 2.9 & 11.8 & 0.0 \\
\hline A pharmacist & 14.7 & 20.6 & 29.4 & 35.3 & 0.0 \\
\hline A counsellor & 86.5 & 2.7 & 0.0 & 8.1 & 32.4 \\
\hline A social worker & 61.8 & 11.8 & 0.0 & 26.4 & 0.0 \\
\hline Telephone counselling service & 38.9 & 5.6 & 11.1 & 44.4 & 0.0 \\
\hline A psychiatrist & 94.6 & 0.0 & 0.0 & 5.4 & 56.8 \\
\hline A psychologist & 91.9 & 0.0 & 0.0 & 8.1 & 10.8 \\
\hline Family member & 55.5 & 5.5 & 0.0 & 38.9 & 0.0 \\
\hline Close friends & 48.6 & 11.4 & 0.0 & 40.0 & 0.0 \\
\hline A naturopath or an herbalist & 8.3 & 19.4 & 50 & 22.3 & 0.0 \\
\hline Clergy, a minister, or a priest & 67.6 & 14.7 & 0.0 & 17.6 & 0.0 \\
\hline On his own & 11.4 & 2.9 & 65.7 & 20.0 & 0.0 \\
\hline \multicolumn{6}{|l|}{ Medicine type $^{b}$} \\
\hline Vitamins \& minerals, tonics, or herbal medicines & 22.6 & 25.8 & 32.3 & 19.3 & \\
\hline Analgesics & 6.5 & 48.4 & 32.2 & 12.9 & \\
\hline Antidepressants & 83.3 & 0.0 & 5.6 & 11.0 & \\
\hline Antibiotics & 3.4 & 41.4 & 37.9 & 17.2 & \\
\hline Sedatives / hypnotics & 53.1 & 6.3 & 15.6 & 25.0 & \\
\hline Antipsychotics & 75.8 & 12.1 & 6.0 & 6.0 & \\
\hline Tranquilizers such as Valium & 56.7 & 16.7 & 13.3 & 13.3 & \\
\hline \multicolumn{6}{|l|}{ Treatment and activities } \\
\hline Becoming more physically active & 60.0 & 2.8 & 14.3 & 22.9 & 2.7 \\
\hline $\begin{array}{l}\text { Reading about people with similar problems and } \\
\text { how they have dealt with them }\end{array}$ & 75.7 & 5.4 & 0.0 & 18.9 & 5.4 \\
\hline Getting out and about more & 60.0 & 5.7 & 5.7 & 28.6 & 0.0 \\
\hline $\begin{array}{l}\text { Courses on relaxation, stress management, } \\
\text { meditation, or yoga }\end{array}$ & 77.8 & 0.0 & 2.8 & 19.4 & 5.4 \\
\hline Cutting out alcohol altogether & 75.7 & 5.4 & 5.4 & 13.5 & 0.0 \\
\hline Psychotherapy & 83.8 & 5.4 & 2.7 & 8.1 & 40.5 \\
\hline Cognitive behavior therapy & 83.3 & 2.8 & 0.0 & 13.9 & 5.4 \\
\hline Hypnosis & 27.8 & 19.4 & 19.4 & 33.3 & 0.0 \\
\hline Admission to a psychiatric ward of a hospital & 63.9 & 11.1 & 5.6 & 19.4 & 16.2 \\
\hline Electroconvulsive therapy (ECT) & 42.8 & 17.1 & 8.6 & 31.4 & 10.8 \\
\hline Having an occasional alcoholic drink to relax & 8.1 & 29.7 & 51.4 & 8.1 & 0.0 \\
\hline A special diet or avoiding certain foods & 18.9 & 27.0 & 13.5 & 35.1 & 0.0 \\
\hline $\begin{array}{l}\text { Consulting a website that gives information about } \\
\text { his problem }\end{array}$ & 37.1 & 14.3 & 17.1 & 31.4 & 0.0 \\
\hline $\begin{array}{l}\text { Consulting an expert using email or the web about } \\
\text { his problem }\end{array}$ & 27.8 & 16.7 & 16.7 & 38.8 & 0.0 \\
\hline $\begin{array}{l}\text { Consulting a book that gives information about his } \\
\text { health problem }\end{array}$ & 35.1 & 24.3 & 10.8 & 29.7 & 0.0 \\
\hline $\begin{array}{l}\text { Receiving information about his problem from a } \\
\text { health educator }\end{array}$ & 73.0 & 8.1 & 2.7 & 16.2 & 5.4 \\
\hline
\end{tabular}

${ }^{a}$ Proportion of the most helpful interventions among all the interventions described in the vignette

b Medicine type did not include the "most helpful" as an option 
Table 2. Percentages of participant's perception and attitudes towards people with a problem like John's

\begin{tabular}{lccc}
\hline Statement & Agree & $\begin{array}{c}\text { Neither agree } \\
\text { or disagree }\end{array}$ & Disagree \\
\hline $\begin{array}{l}\text { People with a problem like John's could snap out of it if } \\
\text { they wanted }\end{array}$ & 34 & 25.7 & 40 \\
A problem like John's is a sign of personal weakness & 16 & 13.5 & 70 \\
John's problem is not a real medical illness & 8.1 & 5.4 & 87 \\
People with a problem like John's are dangerous & 46 & 5.4 & 49 \\
$\begin{array}{l}\text { It is best to avoid people with a problem like John's so } \\
\text { that you don't develop this problem }\end{array}$ & 2.8 & 5.5 & 92 \\
$\begin{array}{l}\text { People with a problem like John's are unpredictable } \\
\text { If I had a problem like John's I would not tell anyone }\end{array}$ & 46 & 21.6 & 32 \\
$\begin{array}{l}\text { I would not employ someone if I knew they had a problem } \\
\text { like John's }\end{array}$ & 11 & 8.3 & 83 \\
$\begin{array}{l}\text { I would not vote for a politician if I knew they had } \\
\text { suffered a problem like John }\end{array}$ & 35 & 10.8 & 61 \\
\hline
\end{tabular}

